\title{
Photo editing: enhancing social media images to reflect appearance ideals
}

Key points

- The majority of images people are exposed to in the mass media have been digitally altered to reflect enhanced western beauty ideals

- $\quad$ Exposure to heavily edited media images can lead to a number of appearance concerns, such as body dissatisfaction, low social self-esteem and body image-related anxiety

- Many individuals are now editing their own images to reflect appearance ideals before sharing them on social media

- Being exposed to idealised images of one's peers on social media might be worse for an individual's body image than exposure to figures in the mass media. This could be because there is more pressure to fit in socially with peers, and their appearance may be perceived as more real and achievable

\begin{abstract}
People are now becoming increasingly aware of the extent to which most mass media images are edited to reflect enhanced western beauty ideals. Although the negative impact these unachievable appearance standards can have on wellbeing is recognised, and there have been attempts to reduce people's exposure to them, there is now a more complex problem at hand. Photo-editing software is now available to almost anyone, and many social media users have begun to alter their own images to reflect these desirable beauty ideals. For this reason, health professionals need to be aware of the prevalence of photo editing, and the potential negative effects of exposure to idealised images of peers on social media.
\end{abstract}

\section{Photo-editing culture and mass media}

Over the past 20 years, digitally altering images using photo-editing software has become increasingly common in traditional forms of mass media (Jones, 2013). In fact, almost all of images of celebrities and models in magazines and adverts are digitally modified to reflect society's beauty ideals (Jones, 2013). Women often appear slim with full breasts, and men are given enhanced muscular physiques (Ricciardelli et al, 2010). The eyes and mouth may also be enlarged, skin airbrushed to remove blemishes or signs of ageing, and hair made thicker (Dove Self-Esteem Project, 2013).

Edited images have been reported to encourage men and women to compare themselves to heavily enhanced and often physically unachievable appearance ideals, which can have a serious negative impact on their wellbeing (Levine and Murnen, 2009; Fernandez and Pritchard, 2012). Exposure to these images in the media has been associated with increased body dissatisfaction (Groesz et al, 2002; Halliwell et al, 2011), low social self-esteem (Fernandez and Pritchard, 2012) and body image-related anxiety (Tucci and Peters, 2008; Swami et al, 2010; Owen and Spencer, 2013). Additionally, internalisation of the thin ideal in females has been found to contribute to unhealthy diet and exercise behaviours and, in some cases, the development of eating disorders (Thompson and Stice, 2001). On the whole, these images can give individuals unrealistic expectations of beauty, ultimately leading to dissatisfaction with their appearance when they cannot be achieved.

In an attempt to reduce the negative effects of these images, the UK, France, and Israel have advocated the use of disclaimer labels on heavily edited media images (Tiggemann et al, 2013). However, labelling images has been found to draw more attention to enhanced areas of the body, further increasing body dissatisfaction in some individuals (Bury et al, 2016). Using a different approach, Sadiq Khan, the Mayor of London, has prohibited all adverts promoting unrealistic female appearance ideals on London transport (BBC News, 2016). Theoretically, preventing exposure to this kind of media could reduce body dissatisfaction; however, some argue that people have been subjected to edited images in popular culture for so long that they have become normalised. Because of this, members of the general population have now begun altering their own social media images in an attempt to fulfil these appearance ideals (Yao et al, 2016). 


\section{From specialist software to social media}

Social media sites, such as Facebook, Twitter and Instagram, are becoming increasingly popular around the world (Fardouly et al, 2015). In the UK, social networking alone accounts for over 50\% of all internet use (Office for National Statistics, 2015). Although social media sites facilitate communication between peer networks (Boyd and Ellison, 2007), one of the most common reasons for use is sharing personal photos (Yao et al, 2016). For instance, over 10 million photographs are uploaded to Facebook every hour (Mayer-Schönberger and Cukier, 2013). These photos are used frequently for making appearancerelated social comparisons, especially by women (Haferkamp et al, 2012).

Increasingly, social media users evaluate their appearance based on photographs of their peers, rather than models or celebrities (Fardouly et al, 2015). In addition, social media also allows users to actively contribute to social comparisons by sharing their own photos, which often present desirable 'online versions' of themselves (Seidman, 2013).

A substantial amount of research has examined the effects of social media use in general, often using women and young girls. These studies have revealed social media use to be associated with body image concerns (Tiggemann and Slater, 2013), negative mood (Fardouly et al, 2015) and the development of eating disorders (Holland and Tiggemann, 2016), especially in those who regularly make appearance comparisons (Leahey et al, 2007). Research findings therefore suggest that exposure to social media affects individuals similarly to that of mass media.

Given the appearance-related nature of social media, and the increasing availability of amateur photo-editing software (Yao et al, 2016), it is unsurprising that many users are now altering their own images to reflect the appearance ideals portrayed in traditional forms of mass media (Manago et al, 2008; Zhao et al, 2008). Some social media sites even facilitate photo enhancement (e.g. Snapchat includes camera filters specifically designed to enhance beauty).

\section{Prevalence of photo editing}

The prevalence of photo editing on social media is not well-documented; however, a survey by the Renfrew Center Foundation (2014) revealed that over $50 \%$ of the 2000 adults they surveyed had previously edited their social media images in some way. Additionally, $70 \%$ of women, and over $50 \%$ of men aged $18-35$ years reported editing their images regularly. This included removing blemishes, altering skin tone and making themselves look thinner.

These numbers may be a cause for concern because evidence suggests that exposure to idealised images of peers on social media is also associated with increased body dissatisfaction in both males and females (Krones et al, 2005; Haferkamp and Krämer, 2011). Moreover, idealised images of peers may cause greater body dissatisfaction than exposure to mass media images (Ferguson et al, 2014; Fardouly et al, 2015). This is thought to be because mass media pictures are perceived to be fictional, whereas the appearance of a peer seems more real and achievable, thus adding more pressure for an individual to achieve a similar look to fit in socially (Ferguson et al, 2014).

Findings from these studies illustrate how important it is for health professionals to be aware of the negative impact social media may have on an individual's psychosocial wellbeing. This is especially relevant to young people, who make up the largest group of social media users, with over $90 \%$ reportedly using social media everyday (Duggan and Smith, 2013).

Additionally, research has discovered that many adolescents consider social media to be an integral part of their social lives (Kirschner and Karpinski, 2010; Woods and Scott, 2016). At a time when self-identity is forming, using social media to understand societal beauty standards may create additional pressure for young people to alter their images (Krayer et al, 2007). This may be particularly harmful because adolescence is a time when body image concerns and disordered eating often starts to develop, especially in females (Campbell and Peebles, 2014; Voelker et al, 2015).

\section{Interventions to promote positive body image}

On a more positive note, several evidence-based interventions have been developed with a view to reduce social comparisons and body dissatisfaction, by promoting healthy body image and increasing media literacy surrounding unrealistic media images. These interventions, such as the Dove Self-Esteem Project (2010) and the Succeed Body Image Programme (Becker and Stice, 2011), have been found to be effective with adolescent girls and young women. Another initiative, Happy Being Me (Richardson and Paxton, 2010), has had positive results with school-aged boys and girls in the UK (Bird et al, 2013).

This is also being adopted in the mass media; a number of companies have launched campaigns which promote diversity in appearance, aiming to reduce the pressure for women to adhere to unattainable appearance ideals. For example, the underwear brand Aerie (2014) now uses models with a range of body sizes and shapes, and does not edit any of its adverts. Additionally, Sport England's (2015) 'This Girl Can' campaign features women of all shapes and sizes enjoying physical activity and appreciating their bodies. 


\section{Conclusion}

Although there is a considerable amount of research on the negative impact of exposure to idealised images in the mass media, relatively little is known about the effects of sharing images of this kind on social media. While photo editing in the mass media can be regulated to some extent, it is near impossible to control the images that individuals share on social media. This may not only further reinforce appearance ideals in society, but also add pressure for individuals to portray themselves in an idealised way. For this reason, it is important for health professionals to be aware of the impact of idealised social media images, especially on young people, as well as the importance of promoting a healthy and realistic body image. 


\section{References}

Aerie (2014) \#aerieREAL. http://tinyurl.com/gm8yd5q (Accessed 14 October 2016)

BBC News (2016) London mayor plans negative body image advert ban on Tube, buses and trains. http://tinyurl.com/go34tg7 (Accessed 14 October 2016)

Becker C, Stice E (2011) SUCCEED Body Image Programme Manual. Oxford University Press, Oxford

Bird EL, Halliwell E, Diedrichs PC, Harcourt D (2013) Happy Being Me in the UK: a controlled evaluation of a school-based body image intervention with pre-adolescent children. Body Image 10(3): 326-34. doi: 10.1016/j. bodyim.2013.02.008

Boyd DM, Ellison NB (2007) Social network sites: definiton, history and scholarship. Journal of Computer-Mediated Communication 13(1): 210-30

Bury B, Tiggemann M, Slater A (2016) The effect of digital alteration disclaimer labels on social comparison and body image: instructions and individual differences. Body Image 17: 136-42

Campbell K, Peebles R (2014) Eating disorders in children and adolescents: state of the art review. Pediatrics 134(3): 582-92. doi: 10.1542/peds.2014- 0194

Dove Self-Esteem Project (2010) Dove Self-Esteem Project. http://selfesteem.dove.co.uk (Accessed 14 October 2016)

Dove Self-Esteem Project (2013) The Evolution video: how images of beauty are manipulated by the media.

http://tinyurl.com/h3kq8d4 (Accessed 14 October 2016)

Duggan M, Smith A (2013) Social media update 2013. http://tinyurl.com/ngkvy98 (Accessed 14 October 2016)

Fardouly J, Diedrichs PC, Vartanian L, Halliwell E (2015) Social comparisons on social media: the impact of Facebook on young womens body image concerns and mood. Body Image 13: 38-45

Ferguson CJ, Muñoz ME, Garza A, Galindo M (2014) Concurrent and prospective analyses of peer, television and social media influences on body dissatisfaction, eating disorder symptoms and life satisfaction in adolescent girls. J Youth Adolesc 43(1): 1-14. doi: 10.1007/s10964-012-9898-9

Fernandez S, Pritchard M (2012) Relationships between self-esteem, media influence and drive for thinness. Eating Behaviours 13(4): $321-5$

Groesz LM, Levine MP, Murnen SK (2002) The effect of experimental presentation of thin media images on body satisfaction: a meta-analytic review. Int J Eat Disord 31(1): 1-16

Haferkamp N, Eimler SC, Papadakis AM, Kruck JV (2012) Men are from Mars, women are from Venus? Examining gender differences in self-presentation on social networking sites. Cyberpsychol Behav Soc Netw 15(2): 91-8. doi: 10.1089/cyber.2011.0151

Haferkamp N, Krämer NC (2011) Social comparison 2.0: examining the effects of online profiles on social-networking sites. Cyberpsychol Behav Soc Netw 14(5): 309-14. doi: 10.1089/cyber.2010.0120

Halliwell E, Malson H, Tischner I (2011) Are contemporary media images which seem to display women as sexually empowered actually harmful to women? Psychology of Women Quarterly 35(1): 38-45

Holland G, Tiggemann M (2016) A systematic review of the impact of the use of social networking sites on body image and disordered eating outcomes. Body Image 17: 100-10. doi: 10.1016/j.bodyim.2016.02.008

Jones M (2013) Media bodies and Photoshop. In: Attwood F, Campbell V, Hunter IQ, Lockyer S, eds. Controversial Images. Palgrave Macmillan UK, Basingstoke

Kirschner PA, Karpinski AC (2010) Facebook and academic performance. Computers in Human Behaviour 26(6): 1237-45 
Krayer A, Ingledew DK, Iphofen R (2007) Social comparison and body image in adolescence: a grounded theory approach. Health Education Research 23(5): 892-903

Krones PG, Stice E, Batres C, Orjada K (2005) In vivo social comparison to a thin-ideal peer promotes body dissatisfaction: a randomized experiment. Int J Eat Disord 38(2): 134-42

Leahey TM, Crowther JH, Mickelson KD (2007) The frequency, nature, and effects of naturally occurring appearance-focused social comparisons. Behav Ther 38(2): 132-43

Levine MP, Murnen SK (2009) "Everybody knows that mass media are/are not (pick one) a cause of eating disorders": a critical review of evidence for a causal link between media, negative body image, and disordered eating in females. Journal of Social and Clinical Psychology 28(1): 9-42

Manago AM, Graham MB, Greenfield PM, Salimkhan G (2008) Self-presentation and gender on MySpace. Journal of Applied Developmental Psychology 29(6): 446-58

Mayer-Schönberger V, Cukier K (2013) Big Data. A Revolution that Will Transform how we Live, Work and Think. John Murray (Publishers), London

Office for National Statistics (2015) Internet access-households and individuals: 2015. http:// tinyurl.com/hfgrqou (Accessed 14 October 2016)

Owen R, Spencer RM (2013) Body ideals in women after viewing images of typical and healthy weight models. Body Image 10(4): 489-94. doi: 10.1016/j.bodyim.2013.04.005

Renfrew Center Foundation (2014) Afraid to be your selfie? Survey reveals most people Photoshop their images. http://tinyurl.com/orsj9zc (Accessed 14 October 2016)

Ricciardelli R, Clow KA, White P (2010) Investigating hegemonic masculinity: portrayals of masculinity in men's lifestyle magazines. Sex Roles 63(1-2): 64-78

Richardson SM, Paxton SJ (2010) An evaluation of a body image intervention based on risk factors for body dissatisfaction: a controlled study with adolescent girls. Int J Eat Disord 43(2): 112-22. doi: 10.1002/eat.20682

Seidman G (2013) Self-presentation and belonging on Facebook: how personality influences social media use and motivations. Personality and Individual Differences 54(3): 402-7

Sport England (2015) This Girl Can. http://tinyurl. com/gnk3be4 (Accessed 14 October 2016)

Swami V, Frederick DA, Aavik T (2010) The attractive female body weight and female body dissatisfaction in 26 countries across 10 world regions: results of the international body project I. Pers Soc Psychol Bull 36(3): 309-25. doi: 10.1177/0146167209359702

Thompson K, Stice E (2001) Thin-ideal internalization: mounting evidence for a new risk factor for body-image disturbance and eating pathology. Current Directions in Psychological Science 10(5): 181-3

Tiggemann M, Slater A (2013) NetGirls: the internet, Facebook, and body image concern in adolescent girls. Int J Eat Disord 46(6): 630-3. doi: 10.1002/ eat.22141

Tiggemann M, Slater A, Bury B, Hawkins K, Firth B (2013) Disclaimer labels on fashion magazine advertisments: effects on social comparison and body dissatisfaction. Body Image 10(1): 45-53. doi: 10.1016/j.bodyim.2012.08.001

Tucci S, Peters J (2008) Media influences on body satisfaction in female students. Psicothema 20(4): 521-52

Voelker DK, Reel JJ, Greenleaf C (2015) Weight status and body image perceptions in adolescents: current perspectives. Adolesc Health Med Ther 6: 149-58. doi: 10.2147/AHMT.S68344

Woods CW, Scott H (2016) \#Sleepyteens: social media use in adolescence in associated with poor sleep quality, anxiety, depression and low self-esteem. Journal of Adolescence 51: 41-9 
Yao QQJ, Perlmutter DD, Liu JZ (2016) What are shaping the ethical bottom line?: Identifying factors influencing young readers' acceptance of digital news photo alteration. Telematics and Informatics 34(1): 124-32

Zhao S, Grasmuck S, Martin J (2008) Identity construction on Facebook: digital empowerment in anchored relationships. Computers in Human Behavior 24(5): 1816-36 